\title{
Acute Delayed Gastric Emptying after Ablation of Atrial Fibrillation: Treatment with Botulinum Toxin Injection
}

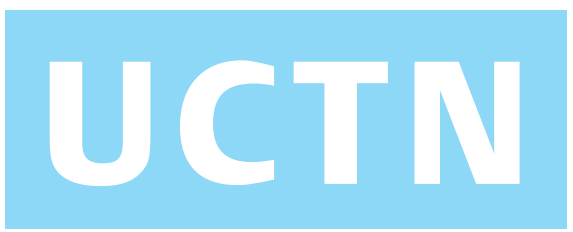

Percutaneous transcatheter radiofrequency (RF) ablation of pulmonary veins is increasingly used for the treatment of refractory atrial fibrillation. With this technique, lesions are created around the ostia of each pulmonary vein to electrically isolate them from the left atrium [1]. We report a case of acute pyloric spasm after RF ablation, which improved after intrapyloric botulinum toxin injection.

A 65-year-old woman underwent uneventful RF pulmonary vein ablation. When she began to eat after the procedure, she developed nausea, epigastric pain, bloating, and belching. Upper gastrointestinal endoscopy showed no esophageal lesion, a stomach full of food, and a pyloric spasm. After endoscopic ultrasonography (Figure 1), 100 units of botulinum toxin type A (Botox; Allergan, Irvine, California, USA) were injected into the pyloric sphincter as described elsewhere [2]. Symptoms improved, and the patient was able to eat semi-solid food, starting 4 hours later. At the time of writing, 5 months after Botox injection, the patient has an almost normal diet with very few symptoms. The upper gastrointestinal discomfort score [3] dropped from a pretreatment value of 360 (range $0-800$ ) to a value of 180 at 5 days after Botox injection, and to 100 at 5 months after treatment. Gastric emptying of liquids also improved, with the half-emptying times before and 5 days after Botox injection being 240 minutes and 159 minutes, respectively (normal value $<89$ minutes).

We speculate that the symptoms observed in our patient were caused by lesions to the left vagal nerve, which runs between the esophagus and the left atrium. This nerve controls pyloric relaxation and antral motility [4]. It is hoped that endoneurial tubes have not been disrupted and vagal nerve function will fully recover over time, so that no repeat Botox injection will be required.

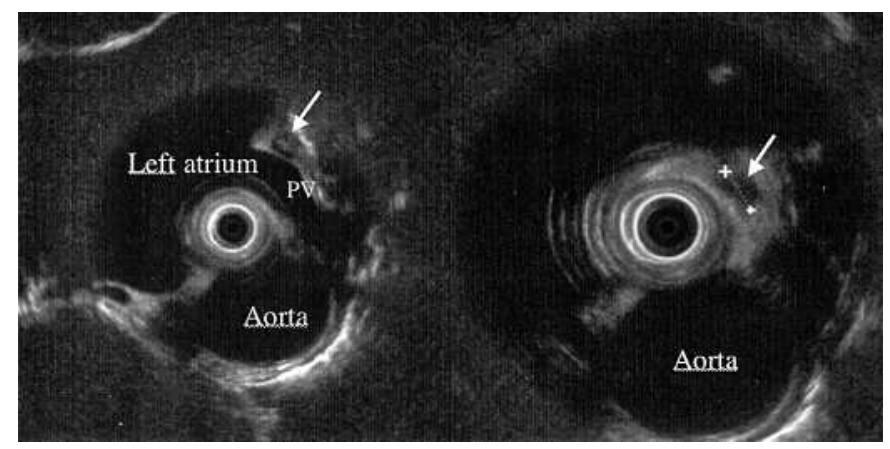

Figure 1 Endoscopic ultrasonography disclosed several hypoechoic lesions (arrows) in the vicinity of the pulmonary veins (PV) and left vagal nerve consistent with hematomas secondary to deep penetration of radiofrequency energy.

J. M. Dumonceau' ${ }^{1}$, E. Giostra' ${ }^{1}$ C. Bech' ${ }^{1}$,
L. Spahr ${ }^{1}$, A. Schroft ${ }^{2}$, D. Shah

${ }^{1}$ Division of Gastroenterology and Hepatology, Geneva University Hospital,

Geneva, Switzerland

2 Division of Cardiology, Geneva University Hospital, Geneva, Switzerland.

\section{References}

${ }^{1}$ Pappone C, Rosanio S, Augello G et al. Mortality, morbidity, and quality of life after circumferential pulmonary vein ablation for atrial fibrillation: outcomes from a controlled nonrandomized long-term study. J Am Coll Cardiol 2003; 42: 185-197

${ }^{2}$ Miller LS, Szych GA, Kantor SB et al. Treatment of idiopathic gastroparesis with injection of botulinum toxin into the pyloric sphincter muscle. Am J Gastroenterol 2002; 97: $1653-1660$

${ }^{3}$ Talley NJ, Verlinden M, Snape W et al. Failure of a motilin receptor agonist (ABT-229) to relieve the symptoms of functional dyspepsia in patients with and without delayed gastric emptying: a randomized doubleblind placebo-controlled trial. Aliment Pharmacol Ther 2000; 14: 1653-1661

${ }^{4}$ Ueno T, Uemura K, Harris MB et al. Role of vagus nerve in postprandial antropyloric coordination in conscious dogs. Am J Physiol Gastrointest Liver Physiol 2005; 288: G487-G495
Corresponding Author

\section{J.-M. Dumonceau, M.D., PhD}

Division of Gastroenterology Geneva University Hospital

Rue Micheli-du-Crest, 24

1205 Geneva

Switzerland

Fax: $\quad$ +41-22-3729366

E-mail: jmdumonceau@hotmail.com 